\title{
Artigo
}

\section{A polissemia do liberalismo: as diferentes abordagens de Wallerstein, Sen e Fukuyama}

The polysemy of liberalism: Wallerstein, Sen and Fukuyama's different approaches

\author{
Leonardo Luiz Silveira da Silva \\ Mestre em relações internacionais e doutorando \\ em Geografia pela PUC-MG. \\ E-mail: <leoluizbh@hotmail.com>.
}

\begin{abstract}
Resumo: Alguns conceitos recorrentes do campo da teoria política têm sido utilizados à revelia, dando margem a ambiguidades que comprometem a interpretação correta de diversas argumentações. Nesta conjuntura, encaixa-se o conceito de liberalismo, que é polissêmico e utilizado em diversos contextos textuais. Compreender a diversidade da utilização do conceito de liberalismo é uma tarefa essencial para os estudantes e profissionais que lidam com teoria política. Para os pesquisadores mais experimentados, estar atento a esta diversidade potencializa os seus instrumentos pedagógicos, pois o conceito de liberalismo é aplicado em contextos textuais tão variados, que podem facilmente, em um mosaico de textos acessíveis aos estudantes, levá-los a análises equivocadas. Este artigo pretende ressaltar a importância da compreensão da polissemia do liberalismo, utilizando-se, para tanto, de três abordagens consagradas das ciências humanas: Após o liberalismo, de Immanuel Wallerstein; O desenvolvimento como liberdade, de Amartya Sem, e O fim da História e o último homem, de Francis Fukuyama. A abordagem distinta destes três autores mostrará algumas possibilidades de leitura ambígua que podem levar os leitores mais descuidados a avaliações precipitadas da utilização do conceito em questão.
\end{abstract}

Palavras-chave: Liberalismo; Immanuel Wallerstein; Amartya Sem; Francis Fukuyama.

\begin{abstract}
Some recurring concepts from the field of political theory haven't been used in the right context, giving rise to ambiguities that compromise the correct interpretation of several arguments. At this juncture fits the concept of liberalism, which is polysemic and used in various textual contexts. Understanding the diversity of the use of the concept of liberalism is an essential task for students and professionals dealing with political theory. For experienced researchers to be aware of this diversity enhances their pedagogical instruments, because the concept of liberalism is applied to textual contexts as varied that could lead them to erroneous analyzes. This article aims to highlight the importance of understanding of the multiple meanings of liberalism, using three approaches of recognized scholars belonging humanities: Immanuel Wallerstein's After Liberalism; Amartya Sen's Development as Freedom and the Francis Fukuyama's End of History. The distinctive approach of these three authors show some possibilities of ambiguous reading that can lead readers to more careless hasty evaluations of the use of the concept in question.
\end{abstract}

Keywords: Liberalism; Immanuel Wallerstein; Amartya Sen; Francis Fukuyama. 


\section{1 - Introdução}

Um grupo de palavras muito usado na ciência política possui um grande universo semântico. A polissemia que caracteriza um conjunto de palavras-chave utilizadas na ciência política conduz à má interpretação, em meio às ambiguidades produzidas em determinados contextos. A dificuldade de comunicação produzida pelas nuances supracitadas atinge professores, pesquisadores e estudantes. Faz-se necessário esmiuçar os diversos sentidos de alguns conceitos para possibilitar diálogos assertivos e potencializar a compreensão de textos acadêmicos. O conceito de liberalismo, termo longamente debatido e pensado no decorrer dos últimos séculos, sendo, portanto, apropriado por diversos grupos com ideologias e intencionalidades distintas, é o alvo desta relativização tão necessária.

A partir dos trabalhos dos autores Immanuel Wallerstein (2002), em Após o liberalismo, Amartya Sen (2000), em Desenvolvimento como liberdade, e Francis Fukuyama (1992), em O fim da História e o último homem, serão apresentadas as diversas apropriações do termo liberalismo. Nessas diferentes formas de abordagem, pretende-se mostrar o quão confuso pode soar o termo liberalismo, fazendo como vítimas preferenciais os estudantes recém-introduzidos nos diversos campos acadêmicos das ciências humanas. Mesmo pesquisadores mais experientes, se apresentados a recortes ou resumos descuidados de ideias que incorporam o conceito, podem criar expectativas equivocadas acerca de suas abordagens.

Este artigo não possui forte base empírica; dessa maneira, pretende ser somente um instrumento útil àqueles que se enveredam pelo campo das ciências humanas, pois, ao mesmo tempo que serve de alerta para a necessidade de relativizações conceituais, possibilita um bom entendimento de trabalhos acadêmicos em diversos níveis. É útil, ainda, para desenvolver a capacidade de interpretação do sentido do liberalismo em textos avançados que não se preocupam em discutir as possibilidades conceituais do termo. Assume-se, contudo, que a polissemia não se esgota nos exemplos dados. Um conceito tão consagrado na ciência política como o do liberalismo já foi empregado em tantos contextos, de forma ora holística, ora reducionista, que seria muita pretensão dar esgotamento às suas múltiplas faces. Já a relevância didática deste trabalho reside na opção à leitura de um texto acessível e que apresenta uma parcela variada do 
entendimento do termo proposto, com a intenção de construir nos estudantes uma noção inicial da necessidade de sua relativização conceitual, abandonando os velhos maniqueísmos pouco salutares à produção do discurso e da construção do saber.

O método utilizado consiste na abordagem de uma obra de cada autor contemplado. O objetivo não é o entendimento da noção do liberalismo no escopo do conjunto de obras de cada autor, o que poderia ser feito devido à vasta bibliografia que a eles se associa. A intenção é justamente destacar as ambiguidades presentes na abordagem de obras específicas, que podem levar as pessoas que não conhecem todo o conjunto de obras dos consagrados intelectuais em questão a confusões semânticas. Afinal, é muito claro que profissionais da envergadura de Wallerstein, Sen e Fukuyama sejam capazes de relativizar o conceito de liberalismo. Isto não está em questão.

\section{2 - Após o liberalismo, de Immanuel Wallerstein}

O contexto dos anos 1980 foi marcante: a crise econômica expressiva conferiu ao período a alcunha de Década Perdida. Os Estados Unidos de Reagan e o Reino Unido de Thatcher experimentavam medidas vislumbradas pela Escola de Chicago, no intento de abandonar a posição de letargia econômica. A URSS de Mikhail Gorbatchev, por sua vez, implementava em 1985 as reformas Perestroyka e Glasnost, transmitindo um claro recado ao bloco socialista de que novos tempos estavam por vir, mesmo que este recado tenha sido transmitido de forma inconsciente. (CASTELLS, 2000) O Muro de Berlim ruiu no mesmo ano em que grandes instituições financeiras internacionais e o governo dos Estados Unidos promoveram o Consenso de Washington (1989). Coincidentemente, é o mesmo ano também das primeiras eleições presidenciais no Brasil, após a redemocratização. Menos coincidência e mais contexto de época foi o cenário que acabou elegendo Fernando Collor de Melo, que se autodenominava o "candidato neoliberal". Dois anos depois, em 1991, a União Soviética desmoronou, fragmentando-se em inúmeras repúblicas que abandonaram a ditadura socialista como forma de sistema de governo.

Todo o contexto da passagem dos anos 1980 para os 1990 fizeram inúmeros pensadores concluírem que a ideologia socialista havia sofrido um duro golpe, enquanto a ideologia liberal ascendia. Escrevendo a sua obra em 1995, sob o título original After 
liberalism, Immanuel Wallerstein chegou a uma conclusão pouco comum aos demais intelectuais do início dos anos 1990:

O colapso da URSS criou dificuldades enormes e talvez insuperáveis para os Estados Unidos. Ficou suprimido o único controle político que os Estados Unidos tinham sobre os seus ora vigorosos rivais econômicos, a Europa Ocidental e o Japão. Embora a dívida norte-americana tenha parado de crescer com o fim do keynesianismo militar, surgiu como consequência um problema gravíssimo de remanejamento econômico, com o qual os Estados Unidos não têm lidado muito bem. E, do ponto de vista ideológico, o colapso do marxismo-leninismo eliminou o último resto de confiança na possibilidade de que reformas conduzidas pelo Estado tragam desenvolvimento econômico considerável às zonas periféricas e semiperiféricas da economia internacional. É por isso que eu tenho afirmado que o suposto colapso dos comunismos foi, na verdade, o colapso do liberalismo como ideologia. (WALLERSTEIN, 1995, p. 70)

Apresentada de forma descontextualizada do conjunto dos seus escritos reunidos em Após o liberalismo, a afirmação de que o desmantelamento do bloco socialista favorece o colapso do liberalismo parece contraditória, fato que se justifica pela grande abundância de obras que apontam o ano de 1991 como o que marca o irrevogável triunfo liberal (como Francis Fukuyama o faz em O fim da História). O autor, conhecido pela contribuição à formulação da teoria do sistema-mundo, preocupa-se com aquilo que chamou de periferia mundial. O continente africano, que estaria na zona periférica, vivencia, após o colapso do bloco socialista, uma crise que não é somente econômica, sendo também ideológica. A desilusão ideológica da África edificou-se devido à crença que se formou no período pós-colonial de que o Estado forte poderia solucionar os problemas econômicos e, por consequência, os sociais. (WALLERSTEIN, 1995, p. 76-77)

Torna-se claro nestes fragmentos o sentido do liberalismo trabalhado pelo autor. Refere-se à não intervenção do Estado na economia. Na sua argumentação, reforça que a crise do liberalismo é a própria crise do sistema capitalista. Considera que o liberalismo já teve a sua hora como projeto político efetivo e que está a caminho de desmoronar sob o impacto da crise estrutural da economia capitalista. Em recente entrevista (LEE, 2012), reafirmou que a economia capitalista mundial está passando por uma crise estrutural que se arrasta desde a década de 1970. 
Para endossar o sentido dado ao liberalismo por Wallerstein nesta obra, é importante a leitura do trecho que se refere ao questionamento liberal (na parcela semântica do termo considerado pelo autor), feito por povos da Europa Oriental no período pós-1991:

Esses povos, em desespero, aceitaram temporariamente os slogans da direita internacional revitalizada, a mitologia do "mercado livre" (um tipo de mercado que, diga-se de passagem, não existe sequer nos Estados Unidos ou na Europa Ocidental), mas essa miragem foi passageira. Já estamos vendo a reversão política na Lituânia, na Polônia, na Hungria e em tantos outros lugares. (IDEM, p. 147)

O autor elenca no livro analisado os quatro grandes problemas estruturais do sistema econômico contemporâneo, possibilitando uma extensão do uso conceitual do liberalismo quando aborda exatamente o quarto problema. Em resumo, esses problemas seriam:

I) a diminuição da oferta de mão de obra barata: implicaria, inevitavelmente, um considerável aumento dos custos do trabalho no mundo inteiro em relação ao custo total da produção mundial;

II) o "aperto" sofrido pelas classes médias: isto é a causa de um conjunto de exigências cada vez maior desta classe, considerada pelo autor como o esteio político do atual sistema internacional, que passa a exigir mais dos empregadores e dos Estados;

III) a pressão ecológica: o maior rigor em relação à preservação ambiental, construído pela formação de uma consciência coletiva e pela formação de regimes internacionais, como o Protocolo de Montreal e o de Kyoto, geram custos econômicos ao atual modelo produtivo;

\section{IV) o abismo demográfico que duplica a brecha econômica entre o Sul e o}

Norte: é conveniente, neste caso, a citação das próprias palavras do autor:

O abismo demográfico que duplica a brecha econômica entre o Sul e o Norte está aumentando ao invés de diminuir. Isto está gerando uma pressão migratória fortíssima do Sul para o Norte, tendo como resultado uma reação política antiliberal não menos forte no Norte. Apesar das barreiras mais severas, a imigração ilegal crescerá em todos os países do Norte, tanto quanto as correntes xenofóbicas. O equilíbrio demográfico interno dos países do Norte mudará drasticamente, causando previsíveis conflitos sociais. (IDEM, p. 149) 
Neste contexto específico, o liberalismo foi utilizado em um novo campo conceitual. O autor alega que o liberalismo está em crise pelo fato de os Estados terem que reforçar a sua fronteira e criar regras mais duras contra a imigração. Essa atitude poderia ser entendida como a manifestação a favor da resistência cultural dos países do Norte, exemplo claro do recrudescimento nacionalista, princípio que coloca a expansão do liberalismo estatal em xeque. Neste caso, o liberalismo é entendido como a natureza permissiva dos limites (territoriais) estatais, no que tange ao controle da imigração.

Em uma última face das abordagens utilizadas sobre o conceito do liberalismo, está o sentido de um regime que defende a universalização dos direitos civis, sem que, contudo, esta premissa posse de fato ser realizada. É uma crítica que aponta para uma incoerência do conceito de liberalismo, que seria uma grave contradição interna em seus princípios, e que vai de encontro com a ideia de Francis Fukuyama (1992), que será trazida posteriormente. Em suas palavras, Immanuel Wallerstein salienta que

em teoria, portanto, proclamava-se a universalidade dos direitos, mas a última coisa que os liberais queriam era que esses princípios liberais fossem tomados ao pé da letra, isto é, aplicados universalmente mesmo. Para que esses princípios não fossem tomados ao pé da letra, o liberalismo precisava de uma força de contenção. Essa força foi o racismo, combinado com o sexismo. É claro que os liberais não poderiam admitir isto, uma vez que tanto o racismo como o sexismo eram, por definição, antiuniversais e antiliberais. (WALLERSTEIN, 1995, p. 160)

O autor reforça ainda o argumento, considerando que

o liberalismo está encurralado pela sua lógica. Continua a afirmar a legitimidade dos direitos humanos e, de maneira um pouco menos enfática, os direitos dos povos. Mas ainda não é isso o que ele quer. Se afirma os direitos, é para evitar que eles sejam plenamente exercidos. Só que isto fica cada vez mais difícil. E os liberais, vendo-se entre a espada e a parede, estão mostrando a sua verdadeira face, voltando maciçamente para o conservadorismo e apenas ocasionalmente para o radicalismo. (IDEM, p. 166)

Em suma, em sua obra Após o liberalismo, Immanuel Wallerstein traz abordagens distintas do conceito de liberalismo. Apesar de ser uma obra muito bem construída, que cumpre o que propõe (trazer a ideia de que a decadência do socialismo como modelo estatal também representou a decadência do socialismo), pode conduzir leitores 
descuidados a confusões semânticas. O liberalismo é apresentado nesta obra como a não intervenção do Estado na economia, como a permissividade das fronteiras estatais, no que tange às imigrações internacionais, e como um regime que promete liberdades civis e que não as cumpre ao criar mecanismos de contenção da universalização destas liberdades. O liberalismo pode ser tudo isso, mas, ao utilizarmos esta palavra, podemos estar nos referindo somente a uma dessas situações e não às outras.

\section{3- O desenvolvimento como liberdade, de Amartya Sen}

O professor e economista Amartya Sen contribuiu para desmitificar as muitas vezes injusta acusação que recai sobre os seus colegas de profissão: a noção de que os economistas supervalorizam as estatísticas e os números quando pensam em planejamento social. Premiado em 1998 com o prêmio Nobel da economia, o professor indiano colaborou para a criação do IDH (Índice de Desenvolvimento Humano) ao lado do seu colega paquistanês Mahub UI Haq. As características peculiares do IDH sintetizam (não refletem) a contribuição teórica que Sen deixou de legado para os estudos do desenvolvimento.

Sen propõe uma abordagem holística da noção de desenvolvimento, rompendo com as antigas tradições que correlacionavam desenvolvimento e desempenho econômico, através do levantamento de dados como o PIB, PIB per capita e Renda per capita. O IDH, por sua vez, ao considerar em sua fórmula dados como o PIB per capita, a EXpectativa de Vida ao Nascer, os Anos de Estudo e os Anos Esperados de Estudo, mostra a pretensão dos seus idealizadores de apresentar um indicador que abrange em seu escopo diversas possibilidades de mensurar o desenvolvimento.

Em Desenvolvimento como liberdade, Sen defende a noção de que o desenvolvimento deve ser medido através da expansão das liberdades reais das pessoas. Para o teórico em questão, a expansão das liberdades humanas promove o desenvolvimento em um sentido mais holístico do termo. A amplitude da noção de liberdade como forma de avaliar o desenvolvimento é demonstrada neste trecho:

Um número imenso de pessoas em todo o mundo é vítima de várias formas de privação de liberdade. Fomes coletivas continuam a ocorrer em determinadas regiões, negando a milhões a liberdade básica de sobreviver. Mesmo nos países que já 
não são esporadicamente devastados por fomes coletivas, a subnutrição pode afetar numerosos seres humanos vulneráveis. Além disso, muitas pessoas têm pouco acesso a serviços de saúde, saneamento básico ou água tratada, e passam a vida lutando contra uma morbidez desnecessária, com frequência sucumbindo à morte prematura. Nos países mais ricos, é demasiado comum haver pessoas imensamente desfavorecidas, carentes de oportunidades básicas de acesso a serviços de saúde, educação funcional, emprego remunerado ou segurança econômica e social. Mesmo em países muito ricos, às vezes a longevidade de grupos substanciais não é mais elevada do que em muitas economias mais pobres do chamado Terceiro Mundo. Adicionalmente, a desigualdade entre homens e mulheres afeta - e, às vezes, encerra prematuramente - a vida de milhões de mulheres e, de modos diferentes, restringe em altíssimo grau as liberdades substantivas para o sexo feminino. (SEN, 2000, p. 29)

Para garantir a expansão das liberdades individuais como forma de promoção do desenvolvimento, o autor aponta ser necessário o atendimento de cinco requisitos que ele chama de liberdades instrumentais. Estas seriam condições sine qua non para a construção de um regime em que as pessoas desfrutariam de liberdades plenas. $\mathrm{Na}$ visão do autor são liberdades instrumentais:

I) as liberdades políticas: que se referem às oportunidades que as pessoas têm para determinar quem deve governar e com que base e com quais princípios. Inclui a garantia de fiscalizar e criticar as autoridades e de ter liberdade de expressão política e usufruir de uma imprensa livre de censura;

II) as facilidades econômicas: que são as oportunidades que os indivíduos têm de utilizar recursos econômicos com propósito de consumo, produção ou troca;

III) as oportunidades sociais: que são as disposições que a sociedade estabelece nas áreas de educação, saúde etc., as quais influenciam a liberdade substantiva de o indivíduo viver melhor;

IV) as garantias de transparência: que se referem às necessidades de sinceridade que as pessoas podem esperar: a liberdade de lidar uns com os outros com dessegredo e clareza. Essas garantias têm um claro papel instrumental como inibidores da corrupção, da irresponsabilidade financeira e das transações ilícitas;

V) a segurança protetora: que é necessária para proporcionar uma rede de segurança social, impedindo que a população afetada seja reduzida à miséria abjeta e, em alguns casos, até mesmo à fome e à morte. (SEN, 2000) 
A noção do liberalismo de Sen manifesta-se no seu modelo de desenvolvimento, baseado na expansão das liberdades individuais. Preocupa-se em vários pontos de sua obra com as desigualdades das oportunidades de que desfrutam os indivíduos de uma mesma sociedade, que é justamente uma das críticas proferidas por Wallerstein a respeito do liberalismo (especificamente quando o autor aponta para as contradições da proposta liberal quanto à impossibilidade de garantir a universalização dos direitos civis, que, a seu ver, é um dos seus princípios). Ao propor as cinco liberdades instrumentais como condições para a expansão das liberdades individuais e, portanto, do desenvolvimento, Sen convida sutilmente o Estado a ser o provedor das mesmas. Contudo, considera que não somente o Estado deve ser o responsável pela promoção das liberdades individuais, como fica claro neste trecho:

O comprometimento social com a liberdade individual obviamente não precisa atuar apenas por meio do Estado; deve envolver também outras instituições: organizações políticas e sociais, disposições de bases comunitárias, instituições não governamentais de vários tipos, a mídia e outros meios de comunicação e entendimento público, bem como as instituições que permitem o funcionamento de mercados e relações contratuais. (SEN, 2000, p. 323,323)

Este fato entra, aparentemente, em contradição com a noção inicial de Wallerstein, e que é amplamente alardeada pelo senso comum, de que o liberalismo é o regime que deveria oferecer a mínima participação do Estado na economia e na sociedade. Contudo, vimos que Wallerstein é cético quanto à operacionalização do regime liberal, pelo mesmo possuir graves contradições internas. Ao propor a intermediação do Estado como forma de promover as liberdades individuais, Sen retira o liberalismo de sua forma mais pura do campo da utopia e propõe uma espécie de "liberalismo realizável". De forma grosseira, é plausível admitir que não há discordância conceitual entre os dois autores neste ponto. O ceticismo de Wallerstein se baseia em uma lógica conjuntural, em que o contexto do desenvolvimento histórico e o momento do capitalismo adicionam barreiras intransponíveis para o exercício do liberalismo.

No grande campo conceitual do liberalismo, Sen está na interseção de Wallerstein: ambos entendem a universalização dos direitos civis como a máxima expressão dos ideais liberais. A avaliação pessimista de Wallerstein, em contradição com o pragmatismo de Sen (que centra a possibilidade de universalização dos direitos civis no nível 
operacional), transmite uma ideia aos mais descuidados de que ambos estão se referindo a conceitos distintos. De fato, o meio de obtenção da universalização supracitada se mostra diferente: Wallerstein diz que o liberalismo sozinho não dá conta de fazê-la, e Sen acredita que o Estado deve atuar na sociedade, pois somente assim os cidadãos de diferentes classes gozarão, de fato, das liberdades individuais em sua máxima expressão.

Sen mostra de maneira didática, em uma entrevista que deu à revista Veja, em 2012, o campo em que coloca o liberalismo, ao rejeitar o maniqueísmo desenvolvimentista que se apresenta na oposição entre Milton Friedman e John Maynard Keynes e ressaltar aspectos positivos da obra de Adam Smith, em pontos que justamente endossam o seu entendimento da noção de desenvolvimento como expansão das liberdades individuais:

Os seguidores de Friedman erram ao imaginar que a economia de mercado pode fazer tudo sozinha. É um modelo impossível de ser implementado no mundo real. Os keynesianos erram ao pensar que o mero estímulo da demanda vai resolver todos os problemas econômicos. Keynes tem relevância apenas quando estamos lidando com uma recessão. Mas ele diz muito pouco sobre o papel do governo como propulsor do desenvolvimento. Para saber como deve agir o Estado, é preciso buscar respostas em Adam Smith, ou em Arthur Pigou (economista inglês, 1877-1959), que tratou de questões como pobreza, desigualdade, qualidade da moradia, educação. Keynes nada tem a acrescentar a respeito desses temas. O desenvolvimento resulta de investimentos em fatores cruciais como educação, saúde, segurança individual e, é claro, disseminação do conhecimento. Sinto pelos seguidores deles, mas em nenhum desses aspectos Keynes ou Friedman têm muito a dizer. (SEN, 2012, p. 19)

O trecho da entrevista sintetiza o pensamento trazido pelo livro Desenvolvimento como liberdade. Fica claro diante do exposto que, para Sen, a universalização de direitos civis é um bem maior do que a não intervenção do Estado. Além disso, rompeu com a associação muito comum que se faz de Adam Smith com a ausência completa do Estado na sociedade. O liberalismo na visão de Sen é a universalização dos direitos civis, considerando, contudo, a participação do Estado em conjunto com a iniciativa privada como seus provedores. Em suma, Wallerstein e Sen possuem congruências na semântica do termo liberalismo, mas que precisam ser esmiuçadas para evitar avaliações equivocadas. 


\section{4 - O fim da História e o último homem, de Francis Fukuyama}

A teoria do Fim da História na versão de Fukuyama surge no contexto do colapso da bipolaridade da Guerra Fria e trata-se de uma tentativa de leitura de um mundo que se reorganiza. No ano de 1989, no periódico The National Interest, o professor Francis Fukuyama resgatou em um artigo a expressão não original "Fim da História", já utilizada outrora por Hegel, Marx e Kojève com outros significados. Colocando o título do seu texto em interrogação, Fukuyama utilizou o contexto do final da década de 1980 para afirmar que a história estava chegando ao fim. Não quis dizer que, com isso, haveria uma suspensão dos acontecimentos relevantes, em que os jornais não teriam mais o que noticiar. Fica clara em sua argumentação, tanto em seu artigo quanto no livro que desenvolveu a partir de sua publicação inicial, que o Fim da História seria o triunfo definitivo da democracia liberal.

Para Fukuyama, o mundo dá sinais de que o Fim da História, a partir da perspectiva democrática e liberal, está próximo. A decadência do totalitarismo socialista, registrado de forma aguda na década de 1980, e a adoção de medidas liberalizantes em diversos regimes políticos são, em sua visão, tentativas de aperfeiçoamento da administração dos governos. O grande crescimento econômico na década em questão, registrado nos chamados tigres asiáticos - grupo de países que haviam adotado princípios liberais em sua gestão - contrastava com a estagnação de regimes socialistas como o da China. A pujança e a letargia econômica estavam lado a lado nas duas Coreias, proporcionando explicações fáceis para quem quisesse entender as origens das diferenças exibidas entre Seul e Pyongyang. A tentação liberal corrompeu os princípios estatizantes e intervencionistas do socialismo na China e convidou o Leste europeu à revolução, inspirados, sobretudo, pela valsa tocada em Moscou, cuja melodia insistia em duas notas: a Perestroika e a Glasnost. Sobre as claras tendências e as mudanças da década de 1980, escreveu Fukuyama:

O milagre econômico do Leste da Ásia foi atentamente observado no mundo todo, mas em nenhum lugar com tanto cuidado quanto no bloco comunista. A crise final do comunismo começou, de certa forma, quando os líderes chineses reconheceram que estavam sendo deixados para trás pelo resto da Ásia capitalista, e perceberam que o planejamento central socialista havia condenado a China ao atraso e à pobreza. As reformas liberalizantes que se seguiram na China fizeram duplicar a 
produção de cereais em cinco anos, dando uma nova demonstração do poder dos princípios de mercado (...)

(...) Porém, os países do bloco comunista não eram os únicos observadores do milagre econômico do Leste da Ásia. Uma transformação notável processou-se também no pensamento econômico da América Latina. Na década de 1950, quando o economista argentino Raul Prébisch presidia o comitê econômico das Nações Unidas para a América Latina, era moda atribuir o subdesenvolvimento não só da América Latina, mas do terceiro mundo principalmente, ao sistema capitalista global. Argumentava-se que os iniciadores do sistema, na Europa e nos Estados Unidos, haviam estruturado a economia mundial a seu favor, condenando os que viessem depois a posições dependentes como fornecedores de matéria-prima. No começo da década de 90 essa ideia havia mudado completamente. O presidente Carlos Salinas de Gortari, no México, o presidente Carlos Menem, na Argentina, e o presidente Fernando Collor de Mello, no Brasil, procuraram implementar programas de liberalização econômica de longo alcance, logo que tomaram posse, aceitando a necessidade da competição do mercado e a abertura para a economia mundial. (...)

(...) Esses novos líderes democraticamente eleitos partiram da premissa de que o subdesenvolvimento não era devido às desigualdades inerentes ao capitalismo, mas ao grau insuficiente de capitalismo praticado nos seus países no passado. A privatização e o mercado livre tornaram-se as novas senhas, no lugar da nacionalização e substituição de importação. (FUKUYAMA, 1992, p. 71-72)

Na visão de Fukuyama, pelo fato de a democracia e o liberalismo não possuírem graves contradições internas, não haveria motivo para que ocorressem revoluções que buscassem a sua substituição. Faz, com tudo, um alerta:

Não significa que as democracias estáveis atuais, como os Estados Unidos, a França ou a Suíça, estejam isentas de injustiças e sérios problemas sociais. Porém, são problemas de implementação incompleta dos princípios de liberdade e igualdade, nos quais essas democracias se baseiam, e não oriundos de falhas nos próprios princípios. Embora alguns países contemporâneos não chegassem a alcançar uma democracia liberal estável, e outros revertessem para outras formas mais primitivas de governo, como a teocracia ou a ditadura militar, não seria possível aperfeiçoar o ideal da democracia liberal. (FUKUYAMA, 1992, p. 11)

Ao posicionar a democracia liberal como um regime livre de contradições internas, Fukuyama contesta a visão de Wallerstein, que é, por sua vez, cética quanto à capacidade do liberalismo de realizar uma de suas principais promessas: a universalização dos direitos civis. Como toca na expressão "democracia liberal" em diversos momentos de 
sua obra (afinal, é a democracia liberal o pilar para a consolidação do Fim da História), Fukuyama faz questão de definir bem estes termos. Quando fala de liberalismo, refere-se a alguns direitos civis, restringindo o seu campo semântico à seguinte definição: "uma norma jurídica que reconhece certos direitos ou liberdades individuais que escapam do controle do governo" (IDEM, p. 73). Quanto a estes direitos fundamentais, Fukuyama argumenta:

Existem várias definições dos direitos fundamentais. Usaremos a obra clássica de Bryce sobre a democracia, que os limita a três: direitos civis, "a isenção de controle do cidadão no que se refere à sua pessoa e às suas propriedades"; direitos religiosos, "isenção de controle na expressão de opiniões religiosas e na prática da religião"; e o que ele chama de direitos políticos, "isenção de controle em assuntos que não afetam diretamente o bem-estar de toda a comunidade a ponto de tornar o controle necessário", incluindo o direito fundamental de liberdade de imprensa." (FUKUYAMA, 1992, p. 73)

Os direitos civis apresentados como pilares do liberalismo para Fukuyama são mais restritos do que aqueles contidos na noção trazida por Amartya Sen quanto às liberdades individuais, afinal, o economista indiano mostra-se cético quanto à universalização dos direitos civis sem a participação do Estado.

É necessário trazer a definição de democracia feita por Fukuyama, à medida que a expressão democracia liberal é empregada largamente. Assim, é possível separarmos o conceito das duas palavras na visão do cientista político norte-americano, no intuito de compreendermos com clareza até onde vai o liberalismo (do ponto de vista conceitual) e quais são os limites da democracia em suas definições. Por democracia, considera "o direito universal de todos os cidadãos de participar do poder político, ou seja, o direito universal de voto e de participação na política" (IDEM, p. 74). Tal definição foi incluída por Sen no escopo da definição de liberalismo, na forma de uma de suas liberdades instrumentais (liberdades políticas). Fukuyama argumenta ainda sobre os dois conceitos que:

Embora democracia e liberalismo caminhem sempre juntos, é possível separá-los teoricamente. É possível a um país ser liberal sem ser especificamente democrático, como a Grã-Bretanha do século XVIII. Uma vasta lista de direitos, incluindo o direito de voto, era assegurada a uma pequena elite social, mas negada a outros. É possível também a um país ser democrático sem ser liberal, isto é, sem proteger os direitos dos indivíduos e das minorias. Um bom exemplo é a república islâmica do Irã, que tem 
realizado eleições regulares razoavelmente limpas pelos padrões do Terceiro Mundo, tornando o país mais democrático do que era no tempo do Xá. Entretanto, o Irã islâmico não é um Estado liberal. Não há garantias de liberdade de expressão, de reunião e, acima de tudo, de religião. Os direitos mais elementares dos cidadãos iranianos não são protegidos por norma jurídica, uma situação que afeta especialmente as minorias étnicas e religiosas do Irã. (FUKUYAMA, 1992, p. 74)

Assim, de forma categórica, Fukuyama não inclui no escopo conceitual do liberalismo as liberdades políticas na forma de realização de eleições e de participação na vida política. Apesar disso, considera tais liberdades como fundamentais para a consolidação daquilo que chamou de Fim da História. Parte da premissa de que o liberalismo se trata da mínima intervenção do Estado na economia, como ficou claro nos seus argumentos elogiosos ao bom desempenho econômico dos tigres asiáticos no final do século passado. Incluiu, também, no conceito de liberalismo diversas características da liberdade individual, como a liberdade de expressão, direitos religiosos e de propriedade. Por fim adicionou ao conceito a isenção de controle do Estado em assuntos que não afetam diretamente o bem-estar de toda a comunidade, ao ponto de tornar o controle necessário.

\section{5 - Abrangências, congruências e divergências}

Ao afirmar que o liberalismo entrou em crise juntamente com o socialismo, Wallerstein referiu-se ao primeiro como proposta de um Estado minimamente interventor no campo econômico. Ao tentar explicar as razões de sua afirmação pouco comum, destaca o fortalecimento da ideia do controle dos limites (territoriais) por parte do Estado, em um mundo de globalização intensificada e de avanço das migrações internacionais. Nesse sentido, é plausível considerar que o autor adiciona ao campo conceitual do liberalismo a ideia de um Estado permissivo no que diz respeito ao trânsito de pessoas através de seus limites territoriais. Adiciona ainda ao sentido do liberalismo a ideia de que a ideologia trata-se de uma promessa que não se pode cumprir. Para tanto, argumenta que o liberalismo defende em tese a universalização dos direitos civis, sendo incapaz de concebê-los na prática, considerando os seus próprios princípios. 
Para Sen, a universalização dos direitos civis é o bem maior da liberdade. Diferentemente de Wallerstein, não considera que tal universalização seja impossível de ser realizada pelos princípios liberais. Contudo, acredita que o próprio Estado deve atuar no sentido de garantir a universalização dos direitos. Wallerstein deixa subentendido que o Estado poderia fazer este papel, mas a crise do socialismo da década de 1980 teria colocado, na sua visão, esta alternativa em xeque. Sen, por sua vez, não entra nesse mérito e subentende-se que não compartilha dessa visão. Afinal, sua obra Desenvolvimento como liberdade foi publicada originalmente em 1999, e nela consta a participação do Estado como importante agente provedor daquilo que chamou de liberdades instrumentais.

O cientista político Francis Fukuyama considera, assim como Wallerstein, a não intervenção do Estado na economia como princípio liberal. Fukuyama traz uma visão díspar ao fazer a distinção entre o liberalismo e a democracia. Para o autor em questão, o liberalismo inclui a liberdade de expressão, de reunião, de opção religiosa e de uma vasta gama de direitos, sendo todos eles garantidos por uma norma jurídica. A extensão do seu conceito difere do apresentado por Sen no momento em que o cientista político americano argumenta que a ausência do direito ao voto não compromete a definição de liberalismo. Não está clara esta posição na obra de Wallerstein, quando o mesmo utiliza a expressão universalização dos direitos civis. Estas divergências são ocasionadas pela clara opção de Fukuyama de distinguir entre liberalismo e democracia e considerar que é possível haver democracia sem liberalismo e vice-versa.

É possível concluir que as congruências, divergências e abrangências do conceito de liberalismo não são simples e se apresentam diversamente, de acordo com os autores apresentados. É muito provável que o termo seja ainda tratado semanticamente diferente de forma mais sutil ou grosseira, diante dos autores apresentados.

A dificuldade apresentada pela multiplicidade discutida neste artigo alerta para a necessidade de reflexão sobre o escopo conceitual considerado quando o termo é apresentado, seja em forma de leitura, no campo didático ou do discurso. Sem a preocupação com a definição do termo e a apresentação de suas congruências, divergências e abrangências, poderão ser produzidas reflexões simplistas sobre um conceito tão crucial na ciência política. Um olhar bem treinado no que diz respeito a tais multiplicidades potencializa a capacidade interpretativa do indivíduo e poderá melhorar a capacidade de compreensão textual, bem como a capacidade didática e discursiva. 
O universo semântico do liberalismo para Wallerstein (2002), Sen (2000) e Fukuyama (1992)

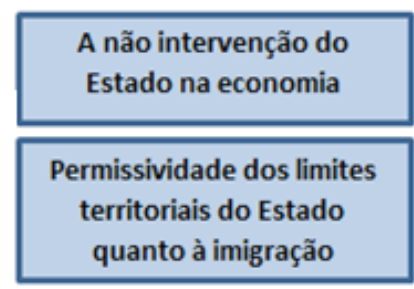

Contraditória ideologia que promete a universalização dos direitos civis e é incapaz de oferecê-la

Immanuel Wallerstein

Amartya Sen

Francis Fukuyama
A universalização dos direitos civis

garantida pela ação do Estado e da iniciativa privada

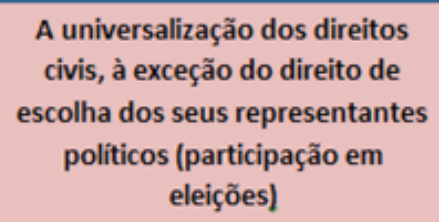

A universalização dos direitos civis, à exceção do direito de escolha dos seus representantes políticos (participação em eleições)

A não intervenção do Estado na economia

Fonte: Organizado pelo próprio autor

\section{6 - Referências bibliográficas}

CASTELLS, Manuel. Fim de milênio. São Paulo: Paz e Terra, 2000.

FUKUYAMA, Francis. O fim da História e o último homem. Rio de Janeiro: Rocco, 1992.

LEE, Su-hoon. "Wallerstein: 'nenhum sistema é para sempre"'. Tradutores: ALBUQUERQUE, Hugo; CASTILHO, Inês. Outras Palavras - Comunicação compartilhada e pós-capitalismo, 12 nov. 2012. Disponível em: <http://outraspalavras.net/posts/wallerstein-nenhum-sistema-e-para-sempre/>. Acesso em: 26 mar. 2014.

REVISTA VEJA. SEN, Amartya. Mercados, justiça e liberdade. São Paulo: Editora Abril, edição de 2 de maio de 2012.

SEN, Amartya Kumar. Desenvo/vimento como liberdade. São Paulo: Companhia das Letras, 2005. WALLERSTEIN, Immanuel. Após o liberalismo. Petrópolis: Vozes, 2002.

Recebido: 02/03/2014

Aceito: $25 / 07 / 2014$ 